\title{
ROLE OF NONLINEAR PROCESSES IN INSTABILITY OF DYNAMICAL SYSTEMS IN ECONOMICS APPLICATIONS
}

\author{
A.S. ZHOKHIN \\ Bogolyubov Institute for Theoretical Physics, Nat. Acad. of Sci. of Ukraine \\ (14b, Metrolohichna Str., Kyiv 03680, Ukraine; e-mail: aszhokhin@bitp. kiev.ua)
}

\begin{abstract}
We study the influence of an external investment on the stability of equilibrium prices in an economic system which is described by the equations of evolution of prices of goods with regard for the balance of supply and demand, as well as the external investment in the economic system. It is shown that sufficiently high levels of investments lead to the loss of stability of the equilibrium state.
\end{abstract}

\section{Introduction}

Economic systems are an example of nonlinear dynamic systems with complicated self-regulation. The processes that occur in them are similar to those in nonlinear physical systems. Therefore, it is possible to apply the methods of modern nonlinear mathematical physics and synergetics, which were successfully used in the study and explanation of nonlinear physical phenomena. The mathematical modeling of economic systems is of interest from the theoretical and applied viewpoints. Mathematical models allow one to explain the temporal evolution of economic processes. Within a sufficiently correct mathematical model, one can analyze a real economic situation and make a forecast of its evolution. On the basis of this forecast, some practical recommendations concerning a change of the economic situation can be given.

Based on models that were proposed in $[1-3,5]$, we develop a model of the evolution of commodity prices in a market economy. Such models are based on the statistical approach to the description of economic processes with the use of the concepts of statistical physics. For the economic system under consideration, a state of equilibrium, which determines the equilibrium price, is of importance. If this equilibrium state is stable, then the economic system under initial conditions in its neighborhood will approach it asymptotically. This is an analogy to the thermodynamic equilibrium in physical systems. For economic systems, we will accept the concepts and methods efficiently operating in physics such as those in the theory of dissipative structures or in nonlinear laser optics. The universality of these methods presents such a possibility. Indeed, for objects of different nature, it is possible to use the same approach, by expanding the regions of the physical description and the methods of studies.

\section{Model}

Let us consider a economic system including $m$ agents, who are the producers and the consumers of $n$ goods. In what follows, we propose a mathematical model of the market economic system characterized by the exchange of goods and the proportional elastic demand.

Prices of goods are described by the vector $p=$ $\left(p_{1}, \ldots, p_{n}\right)$. The market supply of the $i$-th commodity, i.e. its production and initial stocks, is described by the equations

$\Psi_{i} p_{i}=\sum_{k=1}^{m}\left(z_{i k}-x_{i k}\right) p_{i}+\sum_{k=1}^{m} b_{i k} p_{i}$

where $b_{i k}$ is the initial stock of commodities, $z_{i k}$ are their productions, and $x_{i k}$ is the cost of production of commodities, and

$\Psi_{i}=\sum_{k=1}^{m}\left(z_{i k}-x_{i k}\right)+\sum_{k=1}^{m} b_{i k}$

is a vector of commodity stocks. 
On the market, commodities are demanded by consumers. This demand is determined by the demand matrix $\Gamma(p)$, which is a function of prices. As was proposed in [1], the matrix takes the form

$\Gamma_{i k}(p)=\frac{p_{i} c_{i k}}{\sum_{s=1}^{n} p_{s} c_{s k}} ; \quad c_{i k}>0 ; i=1, \ldots, n ; k=1, \ldots, m$,

where $c_{i k}$ are the demand parameters.

The consumers are characterized by a vector function of the income $D(p)$. According to [1], it reads

$D_{k}(p)=\sum_{l=1}^{n} p_{l} D_{k l} ; \quad D_{l k}>0 ; \quad k=1, \ldots, m$,

where $D_{i k}$ are the income parameters.

The demand is expressed as the product of the demand matrix and the income vector, $\Gamma(p) D(p)$. The difference between the vectors of demand and supply is called the excess demand. We denote the vector of excess demand by

$R(p)=\Gamma(p) D(p)-\Psi p$.

The excess demand plays a major role in the formation of the market prices of goods. If it is positive or negative, the prices increase or decrease. If the supply and the demand are equal to each other, i.e. the excess demand is equal to zero, then the prices are equilibrium and are invariant in time.

The evolution of prices is described by the Samuelson equation

$\frac{d p}{d t}=\alpha R(p)$

The explanation of this equation is the following. The price change rate is a function of the excess demand for this product. In a neighborhood of the equilibrium or the zero of the excess demand, this function can be expanded into a Taylor series. The series will include only terms with odd degrees of the excess demand, because the function must be odd. Then we obtain the Samuelson equation in the second order of accuracy. Assuming the universality of price changes, we take coefficient $\alpha$ to be the same for all goods and choose the time scale such that $\alpha=1[3]$.

We assume that the external investments in the form of cash are supplied to the economic system. This changes the production, consumption, incomes, and, as a result, equilibrium prices.
The prices of goods in an economy without external investment

$p_{1}=\left(p_{11}, \ldots, p_{1 n}\right)$

satisfy the system of equations

$\dot{p_{1}}=\Gamma\left(p_{1}\right) D\left(p_{1}\right)-\Psi p_{1}$

or

$\frac{d p_{1 i}}{d t}=\sum_{k=1}^{m} \Gamma_{i k}\left(p_{1}\right) D_{k}\left(p_{1}\right)-\Psi_{i} p_{1 i}, \quad i=1, \ldots, n$.

We denote the vector of external investments by

$M=\left(M_{1}, \ldots, M_{n}\right)$.

The external investments are assets that are introduced into the economic system, which causes changes (increase) in the production of goods. Let the vector

$\Psi_{0}=\left(\Psi_{01}, \ldots, \Psi_{0 n}\right)$

describe the additional production of goods due to investments. Then the prices in the economic system

$p_{2}=\left(p_{21}, \ldots, p_{2 n}\right)$

under investment are described by the equations

$\dot{p_{2}}=\Gamma\left(p_{2}\right)\left(D\left(p_{2}\right)+M\right)-\left(\Psi+\Psi_{0}\right) p_{2}$

or

$\frac{d p_{2 i}}{d t}=\sum_{k=1}^{m} \Gamma_{i k}\left(p_{2}\right)\left(D_{k}\left(p_{2}\right)+M_{k}\right)-\left(\Psi_{i}+\Psi_{0 i}\right) p_{2 i}$,

$i=1, \ldots, n$.

The equilibrium prices $p_{1,2}^{0}$ must satisfy the equality

$\Gamma\left(p_{1}^{0}\right) D\left(p_{1}^{0}\right)=\Psi p_{1}^{0}$

in the absence of investments and

$\Gamma\left(p_{2}^{0}\right)\left(D\left(p_{2}^{0}\right)+M\right)=\left(\Psi+\Psi_{0}\right) p_{2}^{0}$

under investments. Assume that we want to change the production of commodities under investments so that the equilibrium prices will remain the same. In other words, we want to conserve the price situation in the economic system and to keep the price proportions stable. It is a quite understandable economic decision. Then if

$p_{1}^{0}=p_{2}^{0}=p^{0}$, 
then

$\Gamma\left(p^{0}\right) M=\Psi_{0} p^{0}$,

i.e.,

$\sum_{k=1}^{m} \Gamma_{i k}\left(p^{0}\right) M_{k}=\Psi_{0 i} p_{i}^{0}, \quad i=1, \ldots, n$.

So, the parameters of production and investment will be connected by these equations, and the parameter of production of goods $\Psi_{0}$ is fully determined by the parameter of investments $M$.

\section{Time Evolution of the Squared Length of the Vector of Prices}

In nonlinear dynamical systems depending on parameters, the significant role is played by the stability of their trajectories. The special issue is the stability of equilibrium states and, especially, the presence of fixed points in the phase space of a system. The behavior of the trajectories in neighborhoods of these points will be determined by the spectrum at the linearization of the system near the equilibrium state. If the system is globally stable at the equilibrium point, then we need to solve some algebraic equations instead of differential ones. Possessing the linearization spectrum, we will determine the rate of approach of a trajectory to the equilibrium fixed point.

To study the stability of the trajectories of our dynamic economic system, we will apply the methods that were developed in mechanics to determine the stability of motion [7]. We will be interested in the Lyapunov stability of equilibrium prices relative to a perturbation of their initial values. Let us multiply the equations by $p$. We obtain

$\frac{d}{d t}\left(\frac{p_{1 i}^{2}}{2}\right)=p_{1 i} \sum_{k=1}^{m} \Gamma_{i k}\left(p_{1}\right) D_{k}\left(p_{1}\right)-\Psi_{i} p_{1 i}^{2}$,

$\frac{d}{d t}\left(\frac{p_{2 i}^{2}}{2}\right)=p_{2 i} \sum_{k=1}^{m} \Gamma_{i k}\left(p_{2}\right)\left(D_{k}\left(p_{2}\right)+M_{k}\right)-\left(\Psi_{i}+\Psi_{0 i}\right) p_{2 i}^{2}$,

$i=1, \ldots, n$.

Summing up over the variable $i$, we obtain the equations for the rate of change of the squared length of the vector of prices

$\frac{1}{2} \frac{d}{d t}\left(\sum_{i=1}^{n} p_{1 i}^{2}\right)=-\sum_{i=1}^{n} \Psi_{i} p_{1 i}^{2}+\sum_{i, k=1}^{n, m} \Gamma_{i k}\left(p_{1}\right) D_{k}\left(p_{1}\right) p_{1 i}$ in the absence of investments and

$$
\begin{aligned}
& \frac{1}{2} \frac{d}{d t}\left(\sum_{i=1}^{n} p_{2 i}^{2}\right)=-\sum_{i=1}^{n}\left(\Psi_{i}+\Psi_{0 i}\right) p_{2 i}^{2}+ \\
& +\sum_{i, k=1}^{n, m} \Gamma_{i k}\left(p_{2}\right)\left(D_{k}\left(p_{2}\right)+M_{k}\right) p_{2 i}
\end{aligned}
$$

under their presence. We now introduce the functions $L_{1}(p)$ and $L_{2}(p)$ as follows:

$$
\begin{aligned}
& \frac{1}{2} \frac{d}{d t}\left(p_{1}^{2}\right)= \\
& =-\sum_{i=1}^{n} \Psi_{i} p_{1 i}^{2}+\sum_{i, k=1}^{n, m} \Gamma_{i k}\left(p_{1}\right) D_{k}\left(p_{1}\right) p_{1 i} \equiv L_{1}\left(p_{1}\right),
\end{aligned}
$$

$\frac{1}{2} \frac{d}{d t}\left(p_{2}^{2}\right)=-\sum_{i=1}^{n}\left(\Psi_{i}+\Psi_{0 i}\right) p_{2 i}^{2}+$

$+\sum_{i, k=1}^{n, m} \Gamma_{i k}\left(p_{2}\right)\left(D_{k}\left(p_{2}\right)+M_{k}\right) p_{2 i} \equiv L_{2}\left(p_{2}\right)$.

We note that

$L_{2}(p)=L_{1}(p)-\sum_{i=1}^{n} \Psi_{0 i} p_{i}^{2}+\sum_{i, k=1}^{n, m} \Gamma_{i k}(p) M_{k} p_{i}$.

The parameter $\Psi_{0}$ is determined from the relation

$\sum_{k=1}^{m} \Gamma_{i k}\left(p^{0}\right) M_{k}=\Psi_{0 i} p_{i}^{0}$

as

$\Psi_{0 i}=\sum_{k=1}^{m} \Gamma_{i k}\left(p^{0}\right) M_{k} / p_{i}^{0}$.

Thus, we can consider only the independent parameter of investments $M$. Since

$L_{2}(p)=L_{1}(p)-\sum_{i, k=1}^{n, m} \Gamma_{i k}\left(p^{0}\right) M_{k} p_{i} \frac{p_{i}}{p_{i}^{0}}+\sum_{i, k=1}^{n, m} \Gamma_{i k}(p) M_{k} p_{i}$

let us consider the function $L_{3}(p)$, which is determined from the relation

$L_{2}(p)=L_{1}(p)+L_{3}(p)$ 
as

$L_{3}(p)=\sum_{i, k=1}^{n, m} M_{k} \frac{p_{i}}{p_{i}^{0}}\left(\Gamma_{i k}(p) p_{i}^{0}-\Gamma_{i k}\left(p^{0}\right) p_{i}\right)$.

Under conditions of the equilibrium prices, we have

$L_{1}\left(p^{0}\right)=L_{2}\left(p^{0}\right)=L_{3}\left(p^{0}\right)=0$.

Note that $L_{3}(p)$ can be represented in the form

$L_{3}(p)=\sum_{i, k=1}^{n, m} M_{k}\left(\frac{p_{i}^{2} c_{i k}}{\sum_{s}^{n} p_{s} c_{s k}}-\frac{p_{i}^{2} c_{i k}}{\sum_{s}^{n} p_{s}^{0} c_{s k}}\right)$

or

$L_{3}(p)=\sum_{i, k=1}^{n, m} M_{k} p_{i}^{2} c_{i k}\left(\frac{1}{\sum_{s}^{n} p_{s} c_{s k}}-\frac{1}{\sum_{s}^{n} p_{s}^{0} c_{s k}}\right)$.

In addition, we can write

$$
L_{1}(p)=\sum_{i, k, l=1}^{n, m, n} D_{k l}\left(\frac{p_{i}^{2} c_{i k} p_{l}}{\sum_{s}^{n} p_{s} c_{s k}}-\frac{p_{i}^{2} c_{i k} p_{l}^{0}}{\sum_{s}^{n} p_{s}^{0} c_{s k}}\right)
$$

or

$$
L_{1}(p)=\sum_{i, k, l=1}^{n, m, n} p_{i}^{2} c_{i k} D_{k l}\left(\frac{p_{l}}{\sum_{s}^{n} p_{s} c_{s k}}-\frac{p_{l}^{0}}{\sum_{s}^{n} p_{s}^{0} c_{s k}}\right) .
$$

We choose a value $p$ in a neighborhood of the equilibrium point $p^{0}$

$p=p^{0}-\delta p$

$\delta p_{i}>0, i=1, \ldots, n$, where $\delta p$ is a sufficiently small deviation from the equilibrium.

The function $L_{3}(p)$ can be written in the form

$$
L_{3}(p)=\sum_{i, k=1}^{n, m} M_{k}\left(p_{i}^{0}-\delta p_{i}\right)^{2} c_{i k} \times
$$

$$
\times\left(\frac{1}{\sum_{s}^{n}\left(p_{s}^{0}-\delta p_{s}\right) c_{s k}}-\frac{1}{\sum_{s}^{n} p_{s}^{0} c_{s k}}\right) .
$$

Respectively, the function $L_{1}(p)$ reads

$$
L_{1}(p)=\sum_{i, k, l=1}^{n, m} D_{k l}\left(p_{i}^{0}-\delta p_{i}\right)^{2} c_{i k} \times
$$

$$
\times\left(\frac{p_{l}-\delta p_{l}}{\sum_{s}^{n}\left(p_{s}^{0}-\delta p_{s}\right) c_{s k}}-\frac{p_{l}^{0}}{\sum_{s}^{n} p_{s}^{0} c_{s k}}\right) .
$$

Then we perform the transformation

$L_{3}(p)=\sum_{i, k=1}^{n, m}\left(p_{i}^{0}-\delta p_{i}\right)^{2} \frac{c_{i k} M_{k} \sum_{s}^{n} \delta p_{s} c_{s k}}{\sum_{s}^{n}\left(p_{s}^{0}-\delta p_{s}\right) c_{s k} \sum_{s}^{n} p_{s}^{0} c_{s k}}$

and write

$L_{1}(p)=\sum_{i, k, l=1}^{n, m, n}\left(p_{i}^{0}-\delta p_{i}\right)^{2} \frac{c_{i k} D_{k l} \sum_{s}^{n}\left(p_{l}^{0} \delta p_{s}-p_{s}^{0} \delta p_{l}\right) c_{s k}}{\sum_{s}^{n}\left(p_{s}^{0}-\delta p_{s}\right) c_{s k} \sum_{s}^{n} p_{s}^{0} c_{s k}}$.

Moreover, the function $L_{2}(p)=L_{1}(p)+L_{3}(p)$ can be presented in the form

$L_{2}(p)=\sum_{i, k=1}^{n, m}\left(p_{i}^{0}-\delta p_{i}\right)^{2} c_{i k} \times$

$\times \frac{M_{k} \sum_{s}^{n} \delta p_{s} c_{s k}+\sum_{l=1}^{n} D_{k l} \sum_{s}^{n}\left(p_{l}^{0} \delta p_{s}-p_{s}^{0} \delta p_{l}\right) c_{s k}}{\sum_{s}^{n}\left(p_{s}^{0}-\delta p_{s}\right) c_{s k} \sum_{s}^{n} p_{s}^{0} c_{s k}}$.

\section{Problem of Stability of an Equilibrium Price under a Change of the Investment Parameter}

Let the vector of perturbations lie in the region

$\sum_{s=1}^{n} \delta p_{s} c_{s r} \geq 0, \quad \sum_{s=1}^{n} \delta p_{s} p_{s}^{0} \leq 0$,

where $1 \leq r \leq m$. This region is not empty and is a cone. We can find a vector $b$ such that

$\sum_{s=1}^{n} b_{s} c_{s r} \geq 0, \quad \sum_{s=1}^{n} b_{s} p_{s}^{0} \leq 0$.

Then all vectors $\delta p=\epsilon b, \epsilon \geq 0$ will lie in this region and satisfy the condition

$\sum_{s=1}^{n}\left(p_{s}^{2}-p_{s}^{02}\right)=\sum_{s=1}^{n}\left(\delta p_{s}^{02}-2 p_{s}^{0} \delta p_{s}\right) \geq 0$.

In this region, the function $L_{2}(p)$ takes the form

$L_{2}(p)=\sum_{i, k=1}^{n, m}\left(p_{i}^{0}-\epsilon b_{i}\right)^{2} c_{i k} \times$ 


$$
\times \frac{M_{k} \sum_{s}^{n} \epsilon b_{s} c_{s k}+\sum_{l=1}^{n} D_{k l} \sum_{s}^{n}\left(p_{l}^{0} \epsilon b_{s}-p_{s}^{0} \epsilon b_{l}\right) c_{s k}}{\sum_{s}^{n}\left(p_{s}^{0}-\epsilon b_{s}\right) c_{s k} \sum_{s}^{n} p_{s}^{0} c_{s k}},
$$

$L_{2}(p)=\epsilon^{2} L_{2}(\epsilon, b)$,

where $L_{2}(\epsilon, b)$ is

$L_{2}(\epsilon, b)=\sum_{i, k=1}^{n, m}\left(p_{i}^{0}-\epsilon b_{i}\right)^{2} c_{i k} \times$

$$
\times \frac{M_{k} \sum_{s}^{n} b_{s} c_{s k}+\sum_{l=1}^{n} D_{k l} \sum_{s}^{n}\left(p_{l}^{0} b_{s}-p_{s}^{0} b_{l}\right) c_{s k}}{\sum_{s}^{n}\left(p_{s}^{0}-\epsilon b_{s}\right) c_{s k} \sum_{s}^{n} p_{s}^{0} c_{s k}},
$$

Let $M_{r}$ satisfy the inequality

$$
\begin{aligned}
& M_{r} \sum_{i}^{n} p_{i}^{02} c_{i r} \frac{\sum_{s}^{n} b_{s} c_{s r}}{\left(\sum_{s}^{n} p_{s}^{0} c_{s r}\right)^{2}}> \\
& >\sum_{i}^{n} p_{i}^{02} c_{i r} \frac{\sum_{l=1}^{n} D_{r l} \sum_{s}^{n}\left(p_{s}^{0} b_{l}-p_{l}^{0} b_{s}\right) c_{s r}}{\left(\sum_{s}^{n} p_{s}^{0} c_{s r}\right)^{2}}+ \\
& +\sum_{i, k \neq r}^{n, m} p_{i}^{02} c_{i k} \frac{M_{k} \sum_{s}^{n} b_{s} c_{s k}+\sum_{l=1}^{n} D_{k l} \sum_{s}^{n}\left(p_{s}^{0} b_{l}-p_{l}^{0} b_{s}\right) c_{s k}}{\left(\sum_{s}^{n} p_{s}^{0} c_{s k}\right)^{2}} .
\end{aligned}
$$

It is seen from this inequality that we can always choose positive $M_{r}>0$. Then $L_{2}(\epsilon=0, b)=L_{2}(0, b)>$ 0 . By virtue of the continuity of the function $L_{2}(\epsilon, b)$ in $\epsilon$, there exists a neighborhood of zero, where $L_{2}(\epsilon, b)>0$ and $L_{2}(p)>0$ for all sufficiently small $\epsilon>0$. Hence there exists a region in a neighborhood of $p^{0}$, where $L_{2}(p) \geq 0$. In this region, the inequalities

$\sum_{s=1}^{n} \delta p_{s} c_{s r} \geq 0$ and $\sum_{s=1}^{n} \delta p_{s} p_{s}^{0} \leq 0$

are satisfied.

Consider the function

$V(p)=\sum_{s=1}^{n}\left(p_{s}^{2}-p_{s}^{02}\right), \quad \dot{V}(p)=L_{2}(p)$.
In the above-considered region, this function and the time derivative of trajectories will be positive definite. At a fixed point $p^{0}$, we have $V\left(p^{0}\right)=\dot{V}\left(p^{0}\right)=0$. This function can be used as a Chetaev function. Moreover, by the Chetaev theorem [7], the equilibrium state $p^{0}$ is unstable.

In other words, the Lyapunov stability of the equilibrium is violated, and the system will be in the critical state. In this case, the bifurcation can occur, and new solutions, both stationary and nonstationary ones, can appear. The trajectories, which start from a neighborhood of the fixed price $p^{0}$, will move off it and will evolve to other stable modes, which is a favorable result of the loss of stability, or go to infinity with the destruction of the economic dynamics. It is worth noting that the high levels of external investments can be a destabilizing factor for the economic system and can cause its disbalance.

Finding exactly the points of the loss of stability and the bifurcation requires to analyze the equation

$$
\begin{aligned}
& \dot{p}_{i}=\sum_{k=1}^{m} \Gamma_{i k}(p) M_{k}+ \\
& +\sum_{k=1}^{m} \Gamma_{i k}(p) \sum_{l=1}^{n} D_{k l} p_{l}-\left(\Psi_{i}+\Psi_{0 i}\right) p_{i}=X_{i}(p)
\end{aligned}
$$

and to linearize it at the equilibrium point

$A(p) \equiv\left\|\frac{\partial X_{i}(p)}{\partial p_{j}}\right\|$

where

$$
\frac{\partial X_{i}(p)}{\partial p_{j}}=\delta_{i j}\left(\Psi_{i}+\Psi_{0 i}\right)+\sum_{k=1}^{m} M_{k} \frac{\partial \Gamma_{i k}(p)}{\partial p_{j}}+
$$

$+\sum_{k=1}^{n} \Gamma_{i k}(p) \sum_{l=1}^{n} D_{k l} \delta_{l j}+\sum_{k=1}^{n} \frac{\partial \Gamma_{i k}(p)}{\partial p_{j}} \sum_{l=1}^{n} D_{k l} p_{l}$.

In the neighborhood of $p^{0}$, a linear approximation takes the form

$\dot{\delta p}=A\left(p^{0}\right) \delta p$.

The stability of a linear system of the form

$\dot{x}=A x$

is established with the help of the solution of matrix equation

$A^{\prime} Y+Y A=-E$. 
If the matrix $Y$ is positive definite, then the zero solution of the linear system (21) is asymptotically stable.

The criterion for the matrix $Y$ to be positive definite is the Sylvester's one.

The presented equations can be used in the numerical analysis of the stability depending on the vector $M$, since the analytic solution is impossible in the general case.

1. N.S. Gonchar, Mathematical Foundations of Information Economics (BITP, Kiev, 2008).

2. N.S. Gonchar, A.S. Zhokhin, V.G. Kozyrsky, and A.F. Makhort, Probl. Upravl. Inform. 5, 106 (2009).

3. V. Ginsburgh and M. Keyzer, The Structure of Applied General Equilibrium Models (MIT Press,Cambridge, 2002).

4. T. Kehoe, Computationand Multiplicity of Equilibria (Fed. Res. Bank, Minneapolis, 1991).

5. T. Hens, J. Mayer, and B. Pilgrim, Existence of Sunspot Equilibria and Uniqueness of Spot Market Equilibria: The Case if Intrinsically Complete Markets (Univ. of Zurich, Zurich, 2004), Working Paper 188.
6. E. Accinelli, Estudos de Economia 26, 45 (1999).

7. N.G. Chetaev, The Stability of Motion (Pergamon, New York, 1961).

Received 15.02.11

РОЛЬ НЕЛІНІЙНИХ ПРОЦЕСІВ У ВИНИКНЕННІ

НЕСТІЙКОСТІ У ЗАДАЧАХ ДИНАМІЧНИХ

СИСТЕМ ПРИ ЗАСТОСУВАННІ

В ЕКОНОМЦІ

A.C. Жохін

Р е $з$ ю м е

Досліджено вплив зовнішнього інвестування на стійкість рівноважних цін в економічній системі. Економічна система описується за допомогою рівнянь еволюції цін на товари. Розглянуто рівновагу попиту і пропозиції за умови зовнішнього інвестування в економічну систему. Показано, що достатньо високі рівні інвестицій призводять до втрати стійкості рівноважного стану. 